\title{
Inspiratory muscle training in chronic airflow limitation: comparison of two different training loads with a threshold device
}

\author{
C. Lisboa, V. Muñoz, T. Beroiza, A. Leiva, E. Cruz
}

Inspiratory muscle training in chronic airflow limitation: comparison of two different training loads with a threshold device. C. Lisboa, V. Muñoz, T. Beroiza, A. Leiva, E. Cruz. CERS Journals Ltd 1994.

ABSTRACT: The usefulness of inspiratory muscle training (IMT) in chronic airflow limitation (CAL) patients is a controversial issue, mainly due to differences in the training load. To further evaluate this aspect, we studied the effect of the magnitude of the load using a threshold pressure trainer.

Ten CAL patients ( 5 males, 5 females), $67 \pm 2$ yrs (mean \pm SEM) and forced expiratory volume in one second $\left(\mathrm{FEV}_{1}\right) \mathbf{3 6} \pm 2 \%$ pred, were trained for $30 \mathrm{~min}$ a day using a load of $30 \%$ of their maximal inspiratory mouth pressure (PImax) (Group 1). Another 10 CAL patients (5 males, 5 females), $73 \pm 2$ yrs and $\mathrm{FEV}_{1} 37 \pm 2 \%$ pred), were trained using only $12 \%$ of their PImax (Group 2). Training was assessed by PImax, inspiratory muscle power output (IMPO), sustainable inspiratory pressure (SIP), maximal inspiratory flow rate ( $\mathrm{V}$ Imax), pattern of breathing during loaded breathing, Mahler's dyspnoea score, and the 6 min walking distance (6MWD).

After 5 weeks of training, Group 1 exhibited significant increments in: Pimax $(34 \pm 11 \%)$; IMPO (92 $\pm 16 \%)$; SIP (36 $\pm 9 \%)$; and VImax $(34 \pm 13 \%)$. Dyspnoea was also reduced, and the $6 \mathrm{MWD}$ increased by $48 \pm 22 \mathrm{~m}$. We observed no significant changes in Group 2. During loaded breathing, Group 1 showed a significant increment in tidal volume $\left(\mathrm{VT}_{\mathrm{T}}\right)$ and mean inspiratory flow $\left(\mathrm{V}_{\mathrm{T}} / \mathrm{T}_{\mathrm{I}}\right)$, and a reduction in inspiratory time $\left(\mathrm{T}_{\mathrm{I}}\right)$. In Group $2, \mathrm{~V}_{\mathrm{T}}$ and $\mathrm{V}_{\mathrm{T}} / \mathrm{T}_{\mathrm{I}}$ also increased significantly, but the breathing frequency increased with a reduction of expiratory time. When comparing both groups after training, significant differences in PImax, IMPO, Vimax and dyspnoea were observed, with no significant changes in the other parameters.

We conclude that, in patients with chronic airflow limitation, inspiratory muscle training with a high enough load improves inspiratory muscle strength and power output, reduces dyspnoea, and makes the pattern of breathing adequate during loaded breathing. These changes may allow patients to cope better with increased loads imposed by physical effort and exacerbation of symptoms. Eur Respir J., 1994, 7, 1266-1274.

Inspiratory muscle training (IMT) has been used in patients with chronic airflow limitation (CAL) for many years, but results have been controversial [1-8]. This may be attributed, in part, to the different type and magnitude of the load used for training. It is well known that to obtain a given effect when training a skeletal muscle, the stimulus must be specific and sufficient in intensity and duration. Most of the studies in patients with CAL have used an external resistive load which is highly dependent on the pattern of breathing; and, therefore, it is not possible to assure a constant target load which trains the respiratory muscles effectively [8]. This problem can be solved if the patient uses a system to control the pressure or flow developed during training or uses a threshold pressure device, which is independent of the flow rate [9-14]. Whilst studies in which the load is not controlled are controversial, the results of those in which a target load is achieved and maintained have
Departamento de Enfermedades Respiratorias, Escuela de Medicina, Universidad Catolica de Chile, Santiago, Chile.

\section{Correspondence: C. Lisboa}

Departamento de Enfermedades Respiratorias Facultad de Medicina

Universidad Católica de Chile

Marcoleta 345

Santiago

Chile

Keywords: Chronic airflow limitation dyspnoea

inspiratory muscle training

respiratory muscles

Received: August 41993

Accepted after revision February 71994

Supported by Fondecyt Proyecto 715/90. demonstrated that IMT improves inspiratory muscle strength and/or endurance in patients with CAL [9-14].

The magnitude of the load in the studies that use a resistive valve and have a positive effect on inspiratory muscle function is generally over $30 \%$ of their maximal inspiratory mouth pressure (PImax). BELMAN and SHADMEHR used over 50\% Pimax [10]; HARVER et al. employed around 30\% [11]; DeKHUIJZEN et al. [14] trained with a load of 70\%; and Patessio et al. [13] used 50\% Pimax. With threshold inspiratory trainers, on the other hand, the loads used have been between $30-43 \%$ PImax [9, $12]$.

To further evaluate the importance of the target load in patients with CAL, we studied the effects of two different loads using a threshold pressure trainer device. Several indices of respiratory muscle function, together with the breathing strategy, dyspnoea and physical capacity were compared. 


\section{Subjects and methods}

\section{Subjects}

We studied 20 consecutive CAL patients (10 females and 10 males), aged 60-83 yrs, attending our out-patient clinic. In 16 patients, chronic obstruction was associated with smoking; in two with chronic asthma; and in the other two with extensive tuberculosis sequelae. All were in a stable period of their disease and agreed to participate in the protocol, which was approved by the Ethics Committee of our School of Medicine. Their characteristics are summarized in table 1. Inclusion criteria were nonreversible chronic airflow obstruction with dyspnoea on exercise. We excluded patients with unstable obstructive pulmonary disease, cardiac and neoplastic disease, and Pimax lower than $40 \mathrm{cmH}_{2} \mathrm{O}$.

\section{Methods}

The first 10 patients (Group 1) were submitted to inspiratory muscle training (IMT) using a load of $30 \%$ of their Pimax. The next 10 patients (Group 2) followed the same training routine but used the minimal load of the training device $\left(7 \mathrm{cmH}_{2} \mathrm{O}\right)$; this represented approximately $12 \%$ of Pimax in 7 patients, and approximately $17 \%$ of PImax in 3 patients, because of their very low

Table 1. - Baseline characteristics of patients

\begin{tabular}{|c|c|c|}
\hline & Group 1 & Group 2 \\
\hline Sex M/F & $5 / 5$ & $5 / 5$ \\
\hline Age yrs & $67(2)$ & $73(2)$ \\
\hline $\mathrm{FEV}_{1} \%$ pred & $36(2)$ & $37(2)$ \\
\hline FVC $\%$ pred & 81 (4) & $70(6)$ \\
\hline Dyspnoea score & $4.0(0.5)$ & $4.2(0.5)$ \\
\hline $\mathrm{PaO}_{2} \mathrm{kPa}$ & $8.4(0.4)$ & $8.4(0.2)$ \\
\hline $\mathrm{PaCO}_{2} \mathrm{kPa}$ & $5.2(0.1)$ & $5.7(0.2)$ \\
\hline
\end{tabular}

Values are presented as mean with SEM in parenthesis; M: male; $\mathrm{F}$ : female; $\mathrm{FEV}_{1}$ : forced expiratory volume in one second; FVC: forced vital capacity; $\mathrm{PaO}_{2}$ and $\mathrm{PaCO}_{2}$ : arterial oxygen and carbon dioxide tension, respectively; $\%$ pred: percentage of predicted. No significant differences were observed between groups. baseline PImax $(3.9 \mathrm{kPa})$. Training with a threshold inspiratory muscle trainer (Healthscan Products Inc., NJ, USA) was performed at home, for 15 min twice a day, during 6 days a week. All patients were controlled weekly in the laboratory to measure their Pimax and to assure a proper use of the training device, maintaining a duty cycle ( $\mathrm{TI} / \mathrm{Ttot})$ of approximately 0.4 . In the first group, the load was adjusted when necessary, to maintain it equal to $30 \%$ of their Pimax, whilst in Group 2 the load was not modified.

Before training, patients had a one month run-in period, during which treatment with bronchodilators was optimized (including a daily dose of $30 \mathrm{mg}$ of prednisone for the first 7 days). Baseline measurements were performed after this trial. Four patients not included in the study decided not to continue after the run-in period. Their functional data were not different from those of the subjects who completed the study. During this period, spirometry, inspiratory muscle function and dyspnoea were evaluated on three different occasions, and the mean value was used for results. The six minute walking distance (6MWD) was also evaluated on three different occasions, and the highest distance was used for the result. Measurements were performed after the patients had inhaled $300 \mu \mathrm{g}$ of salbutamol through a reservoir. The two groups were not significantly different at the end of the run-in period (tables 1 and 2).

Vital capacity (VC) and forced expiratory volume in one second $\left(\mathrm{FEV}_{1}\right)$ were measured with a dry spirometer (Vitalograph, London, UK). PImax was determined at functional residual capacity (FRC) in a quasistatic way, as proposed by BLACK and HyATT [15] with a Valydine $\mathrm{PM} 45 \pm 150 \mathrm{cmH}_{2} \mathrm{O}$ pressure transducer (Northridge, CA, USA). The values were recorded in a strip-chart recorder (Hewlett Packard, Palo Alto, CA, USA) and the highest value of five technically satisfactory measurements obtained on each study occasion was used for results. Maximal inspiratory flow (Vimax) was measured with a Fleisch No. 4 pneumotachograph attached to a Statham PM5 differential pressure transducer (Hato Rey, Puerto Rico).

Inspiratory muscle power output was measured with the 2 min incremental load method, proposed by MARTYN et al. [16], using a modification of the device described by NiCKERSON and KeENS [17]. The patient breathed during 2 min against the intrinsic load of the device and, subsequently, external weights were added every $2 \mathrm{~min}$.

Table 2. - Effect of training on inspiratory muscle function and on the distance walked in 6 min

\begin{tabular}{|c|c|c|c|c|c|}
\hline & \multicolumn{2}{|c|}{ Group 1} & \multicolumn{2}{|c|}{ Group 2} & \multirow{2}{*}{$\begin{array}{l}\text { IMT differences } \\
\text { between groups }\end{array}$} \\
\hline & Basal & IMT & Basal & IMT & \\
\hline PImax $\mathrm{kPa}$ & $6.4 \quad(0.6)$ & $8.4(0.6)^{* * *}$ & $5.4(0.4)$ & $5.8 \quad(0.4)$ & $*$ \\
\hline IMPO $\mathrm{kPa} \cdot l \cdot \mathrm{s}^{-1}$ & $2.8 \quad(0.4)$ & $5.2(0.7) * *$ & $2.2(0.3)$ & $2.7(0.5)$ & $*$ \\
\hline $\mathrm{SIP} \mathrm{kPa}$ & $4.2(0.4)$ & $5.7 \quad(0.6) * *$ & $3.5 \quad(0.4)$ & $3.9 \quad(0.5)$ & \\
\hline$\dot{\operatorname{V}} \operatorname{Imax} \quad l \cdot \mathrm{s}^{-1}$ & $2.2 \quad(0.3)$ & $2.9(0.2)^{*}$ & $2.3 \quad(0.2)$ & $2.2(0.1)$ & $*$ \\
\hline $6 \mathrm{MWD} \mathrm{m}$ & $373 \quad(49)$ & $432(33)^{*}$ & 298 (34) & 321 (44) & \\
\hline
\end{tabular}

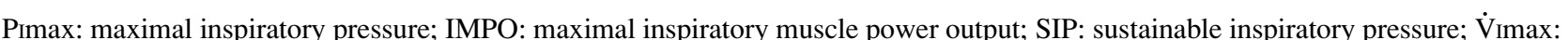
maximal inspiratory flow; 6MWD: distance walked in 6 min; IMT: inspiratory muscle training. *: $\mathrm{p}<0.05 ; * *: \mathrm{p}<0.01 ; * * *: \mathrm{p}<0.001$. 
The first 2 weighed $12.5 \mathrm{~g}$ each, and the rest $25 \mathrm{~g}$ each. The test was finished when the patient was not able to lift the weights or had to stop because of severe dyspnoea. Inspiratory mouth pressure (Pm), inspiratory flow and tidal volume (integrated from flow) were simultaneously registered during the last $30 \mathrm{~s}$ of breathing with each load. Inspiratory muscle power output (IMPO) was calculated for each load by multiplying the inspiratory peak flow (Vinsp) by the peak Pm [16]. Maximal inspiratory pressure which could be sustained for 2 min (SIP) was measured as an index of inspiratory muscle endurance [16].

In order to evaluate the effect of training on the development of fatigue, we calculated the pressure time index (PTX) during loaded breathing, according to Bellemare and Grassino [18]: PTX is the product of peak mouth pressure as a fraction of Pimax, multiplied by $\mathrm{T} /$ /Ttot for each incremental load.

Breathing pattern during loaded breathing was analysed for each of the loads. Tidal volume, inspiratory time (TI), and total duration of the respiratory cycle (Ttot) were measured, and the mean inspiratory flow ( $\left.\mathrm{V}_{\mathrm{T}} / \mathrm{T}_{\mathrm{I}}\right)$ and $\mathrm{TI} /$ Ttot were calculated. In each individual patient, the changes produced by training on the pattern of breathing were practically the same with each of the loads. Therefore, we averaged the values registered in each patient for all of the loads.

Baseline dyspnoea was evaluated using the score proposed by MAHLER et al. [19] and changes after training, by means of their focal transitional index. Physical capacity was assessed with the 6 min walking distance (6MWD) [20].

The training period lasted for $5 \pm 0.8$ weeks in both groups. At the end of the 5 weeks, all of the measurements taken in the run-in period were repeated, after inhalation of $300 \mu \mathrm{g}$ of salbutamol.

No other therapeutic interventions were performed, and drug therapy was not modified during the study period in either group.

\section{Statistical analysis}

Baseline and post-training data were compared within groups using Student's t-test for paired samples. Unpaired Student's t-test was also used to compare pre- and posttraining data between groups. Stepwise regression analysis was used to correlate changes in respiratory muscle function with changes in dyspnoea and 6MWD. Unless otherwise stated, values are expressed as mean \pm SEM. A p-value $\leq 0.05$ was considered significant.

\section{Results}

\section{Inspiratory muscle strength (PImax)}

Figure 1 shows the individual values before and after training in both groups. A significant increment $(34 \pm 11 \%$, mean \pm 1 SEM) was observed in Group $1(\mathrm{p}=0.0013)$ and no changes were observed in Group 2 (table 2). However, in two Group 2 patients, whose baseline Pimax was very low, Pimax increased 20 and 48\%. A significant differ- a)

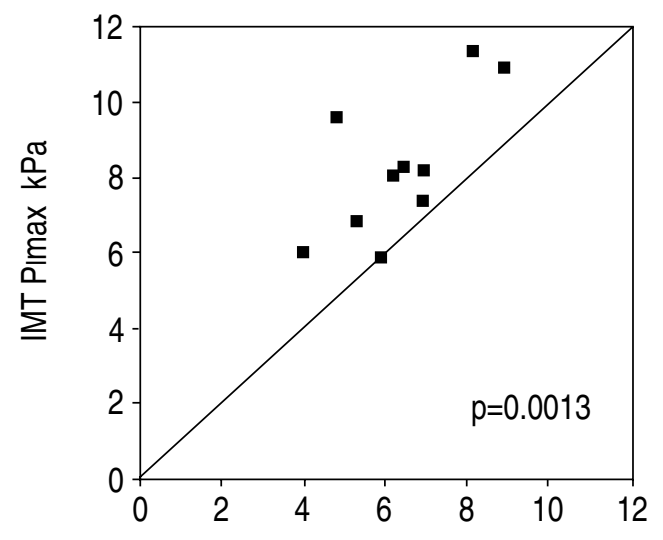

b)

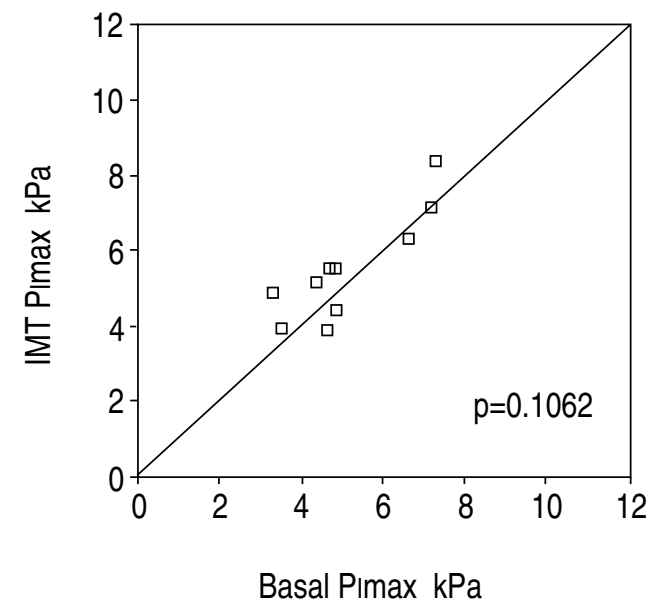

Fig. 1. - Individual values of baseline PImax (horizontal axes) and post-training Pimax (IMT) (vertical axes): a) in Group 1 (घ) and b) in Group 2 (घ). The diagonal line corresponds to the identity line. PImax: maximum inspiratory mouth pressure; IMT: inspiratory muscle training.

ence $(\mathrm{p}<0.012)$ was found when comparing post-training data for both groups (table 2).

\section{Inspiratory muscle power output (IMPO)}

Figure 2 shows the individual values in IMPO, which in Group 1 increased $92 \pm 16 \%(\mathrm{p}=0.0035)$ with training. This increase of IMPO was due to a mean increment of $51 \pm 19 \%$ in Vinsp and $38 \pm 12 \%$ in Pm. In Group 2, however, the average increment observed with training was not significant $(\mathrm{p}=0.37)$ (table 2$)$, although 3 of the 4 patients having the lowest baseline values of IMPO, presented a marked increment in this index after training. When comparing post-training data, IMPO was significantly greater in Group 1 than in Group $2(\mathrm{p}<0.05)$.

\section{Inspiratory muscle endurance (SIP)}

Sustainable inspiratory pressure (SIP) increased significantly with training in Group $1(\mathrm{p}<0.003)$ from $4.2 \pm 0.35$ to $5.7 \pm 0.6 \mathrm{kPa}(36 \pm 9 \%)$; whereas, no significant changes were observed in Group $2(3.5 \pm 0.4$ vs $3.9 \pm 0.5 \mathrm{kPa})$ (fig. 3 and table 2). Although post-training SIP was 
a)

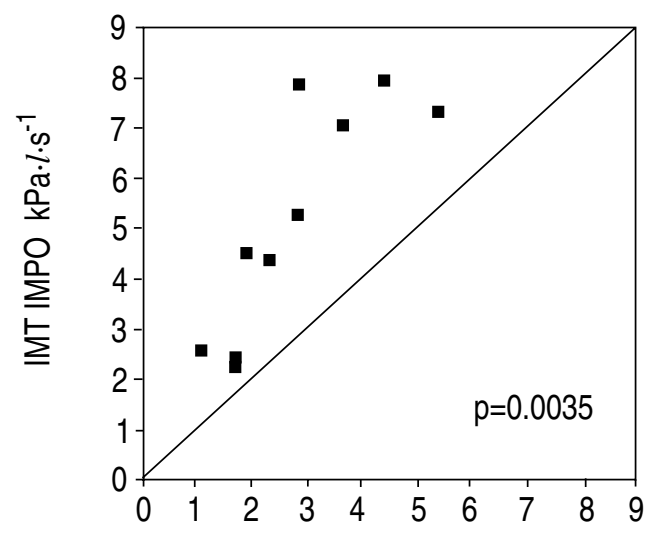

b)

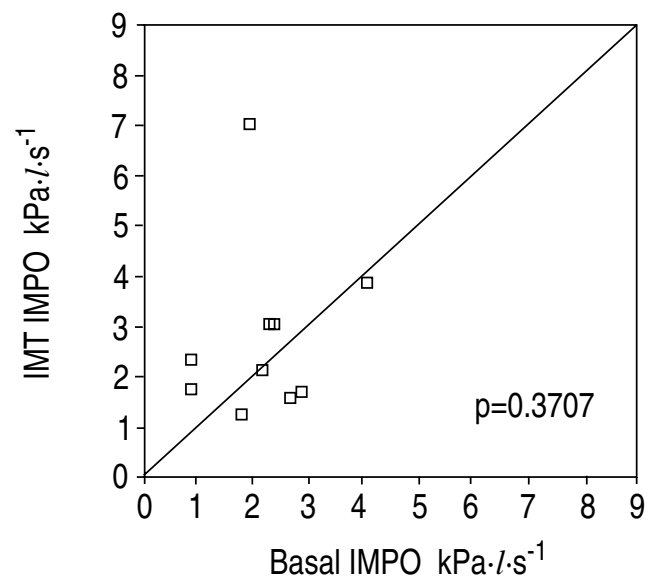

Fig. 2. - Individual values of inspiratory muscle power output (IMPO)

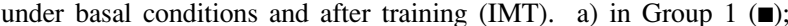
and b) in Group 2 ( $\square$ ). The diagonal line corresponds to the identity line. IMT: inspiratory muscle training.

higher in Group 1 than in Group 2, the difference did not reach statistical significance.

\section{Maximal inspiratory flow}

Vimax increased from baseline, $34 \pm 13 \%$ in Group 1 ( $\mathrm{p}=0.014$ ) and $1.3 \pm 5.8 \%$ (Ns) in Group 2, after 5 weeks of training. Post-training, this index was also significantly higher in Group 1 than in Group $2(\mathrm{p}<0.025)$.

\section{Dyspnoea}

Patients in Groups 1 and 2 had similar dyspnoea scores before training $(4 \pm 0.5$ and $4.2 \pm 0.5$, respectively). The transitional dyspnoea score, improved significantly only in Group $1(\mathrm{p}<0.001)$. This means that patients were able to resume some of their daily activities and/or perform greater tasks or efforts with less dyspnoea. Although 3 of the 10 patients in Group 2 presented a slight increase of the transitional score, these changes were not significant for the group (mean $0.6 \pm 0.54$ points; $\mathrm{p}=\mathrm{NS}$ ). Figure 4 illustrates the individual values observed in both groups. The difference between groups after training was also significant $(\mathrm{p}<0.01)$. a)

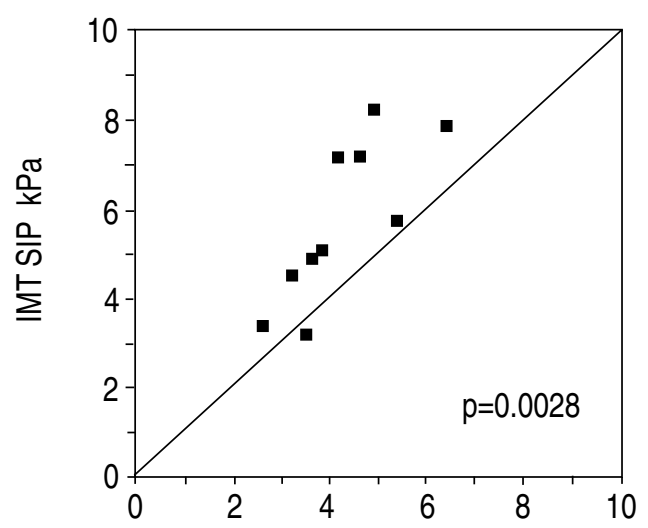

b)

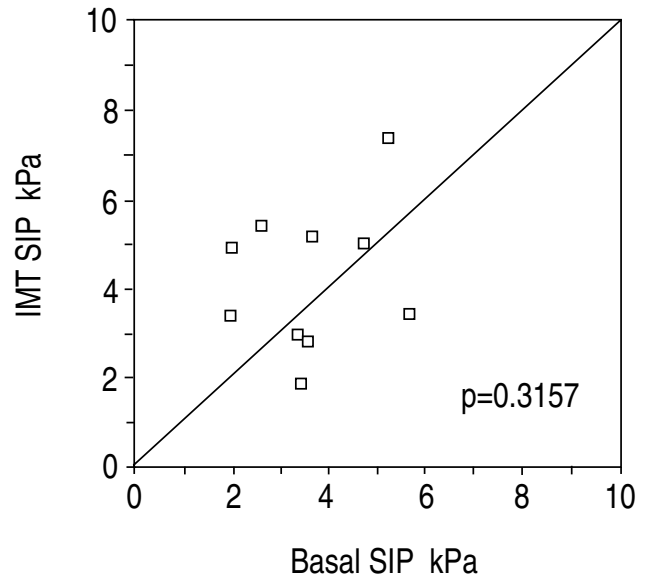

Fig. 3. - Individual values of baseline sustainable inspiratory pressure (SIP) and posttraining SIP (IMT). a) in Group 1 ( $\mathbf{})$; and b) in Group 2 (घ). The diagonal line is the identity line. IMT: inspiratory muscle training.

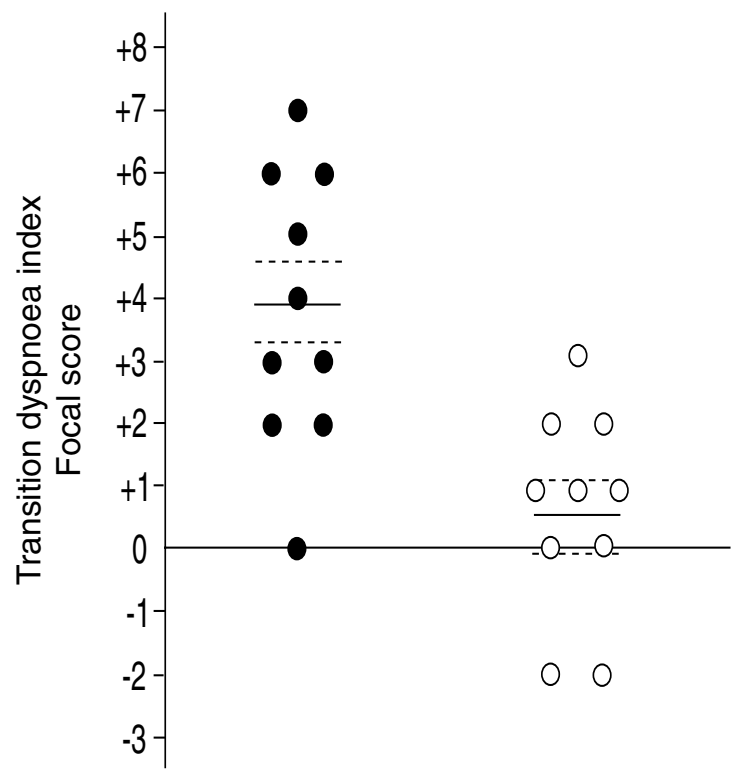

Fig. 4. - Individual values of the transition dyspnoea index in CAL patients after 5 weeks of training in Group $1(0)$ and in Group 2 (O). Horizontal lines are mean \pm 1 SEM. CAL: chronic airways limitation. 
a)

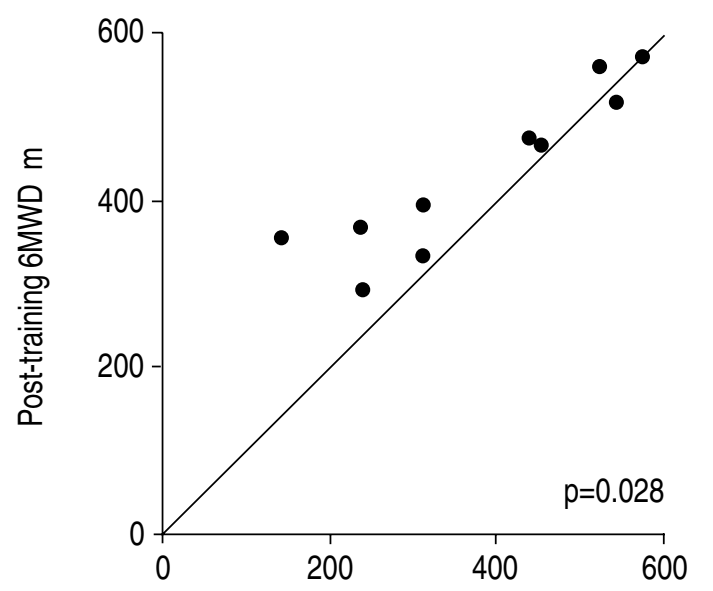

b)

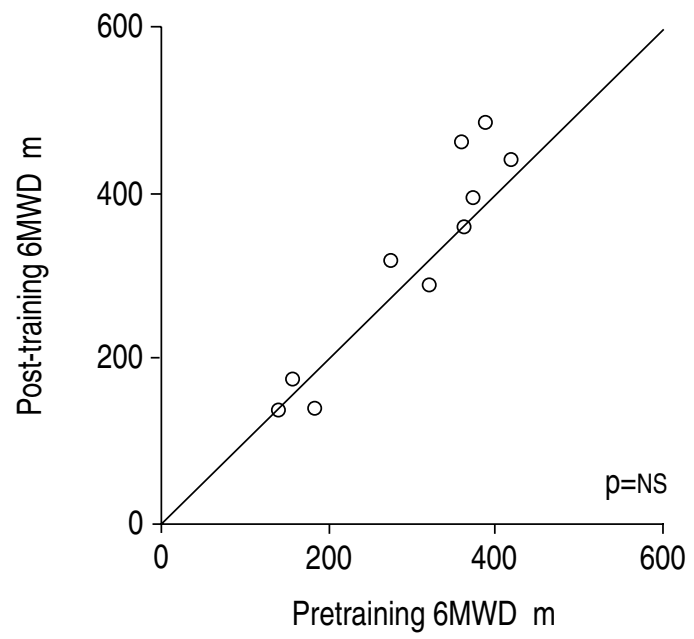

Fig. 5. - Individual values of six minute walking distance (6MWD) before (horizontal axes) and after 5 weeks of training (vertical axes): a) in Group $1(\bullet)$; and b) in Group 2 (०).

No significant relationship was observed in Group 1 between the improvement of dyspnoea at 5 weeks and the changes in IMPO, PImax or SIP. However, when both groups were analysed together, a significant correlation between the percentage change in Pimax and the focal transitional index of dyspnoea was observed $(\mathrm{r}=0.53 ; \mathrm{p}<0.05)$ (not shown).
Six minute walking test (6MWD)

The baseline 6MWD was similar in both groups. In Group 1, a significant increment in the 6MWD was observed after 5 weeks of training (mean $48.4 \pm 21.5 \mathrm{~m}$ ) $(\mathrm{p}<0.025)$, with no significant change in Group 2 (mean $22.3 \pm 16.6 \mathrm{~m}$ ) (Ns). Figure 5 shows the individual values of the 6MWD before and after 5 weeks of training in both groups. Post-training data between Groups 1 and 2 were not statistically significant. A significant inverse correlation between the basal 6MWD and the improvement in walking distance was found in Group 1 ( $\mathrm{r}=-0.82$; $\mathrm{p}<0.01$, whilst we found no significant correlation between the increment in 6MWD and either inspiratory muscle function indices or dyspnoea.

\section{Respiratory cycle during loaded breathing}

The increment of $V_{T}$ in Group 1 was $207 \pm 33 \mathrm{ml}$ $(\mathrm{p}<0.01)$, whereas it was only $86 \pm 42$ in Group 2 . Mean inspiratory flow increased significantly in both groups with training, but this increase was greater in Group 1 (384 \pm 60 versus $215 \pm 34 \mathrm{ml} \cdot \mathrm{s}^{-1}$ ) (table 3$)$. Although inspiratory time ( $\left.\mathrm{T}_{\mathrm{I}}\right)$ also decreased in both groups, it decreased more markedly in Group $1(-0.44 \pm 0.075$ versus $-0.22 \pm 0.03$ s) (table 3).

The total duration of the respiratory cycle increased slightly in Group $1(0.19 \pm 0.3 \mathrm{~s})$ and decreased in Group $2(-0.39 \pm 0.06)$. These differences were significant $(\mathrm{p}<0.001)$. As a consequence, expiratory time (TE) increased in Group 1 from $2.2 \pm 0.17 \mathrm{~s}$ before training to $2.7 \pm 0.41 \mathrm{~s}$ after training, whereas in Group 2 it decreased from $2.2 \pm 0.71$ to $2.0 \pm 0.18 \mathrm{~s}$. This difference, however, was not significant. Figure 6 shows the mean respiratory cycle during loaded breathing before and after training in both groups. No differences were found, however, when comparing post-training data from Groups 1 and 2.

Figure $7 \mathrm{a}$ and $\mathrm{b}$ shows the mean pressure time index (PTX) during breathing with incremental loads before and after training in Groups 1 and 2. As a reference value, we have included the tension time isopleths of the diaphragm (TTdi) described by BELlemare and Grassino [18], which represent the TTdi levels at which diaphragmatic fatigue appears. If we assume that the behaviour of all inspiratory muscles is similar to that of the diaphragm, it may be observed in both groups that the PTX values

Table 3. - Breathing pattern during loaded breathing before and after training

\begin{tabular}{|c|c|c|c|c|c|}
\hline \multirow[b]{3}{*}{ TI $\mathrm{s}$} & \multicolumn{2}{|c|}{ Group 1} & \multicolumn{3}{|c|}{ Group 2} \\
\hline & Basal & IMT & Basal & \multicolumn{2}{|c|}{ IMT } \\
\hline & $1.5 \quad(0.16)$ & $1.1(0.15)^{* * *}$ & $1.1 \quad(0.08)$ & 0.9 & $(0.06)^{*}$ \\
\hline TE $\mathrm{s}$ & $2.2 \quad(0.17)$ & $2.7 \quad(0.40)$ & $2.2 \quad(0.70)$ & 2.0 & $(0.18)$ \\
\hline $\mathrm{TI} / \mathrm{Ttot}$ & $0.40 \quad(0.02)$ & $0.27(0.01)^{* *}$ & $0.35 \quad(0.05)$ & 0.32 & $(0.07)$ \\
\hline $\mathrm{V}_{\mathrm{T}} / \mathrm{TI}_{\mathrm{I}} \mathrm{ml} \cdot \mathrm{s}^{-1}$ & 422 (45) & $806 \quad(58) * * *$ & $461 \quad(36)$ & 677 & $(91)^{*}$ \\
\hline $\mathrm{V}_{\mathrm{T}} \mathrm{ml}$ & $596 \quad(74)$ & $803 \quad(98) * *$ & $515 \quad(51)$ & 601 & (84) \\
\hline $\mathrm{RR}$ bpm & 17.3 & 18.2 & $19.2 \quad(1.3)$ & 22.0 & (1.8) \\
\hline
\end{tabular}

TI: inspiratory time; TE: expiratory time; TI/Ttot: relationship between inspiratory time and the duration of the respiratory cycle; VT/TI: mean inspiratory flow; VT: tidal volume; RR: respiratory frequency; IMT: inspiratory muscle training. No differences were observed between groups after training. *: $\mathrm{p}<0.05 ; * *: \mathrm{p}<0.01 ; * * *$ : $\mathrm{p}<0.001$. 
a)

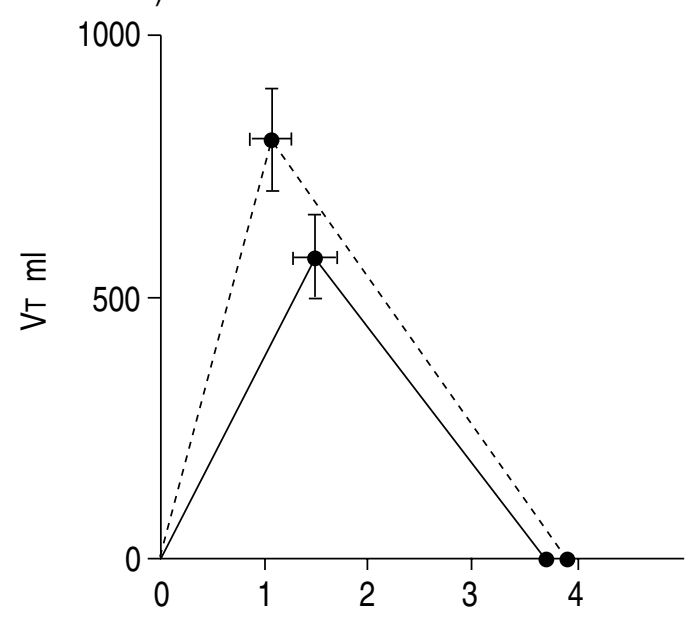

b)

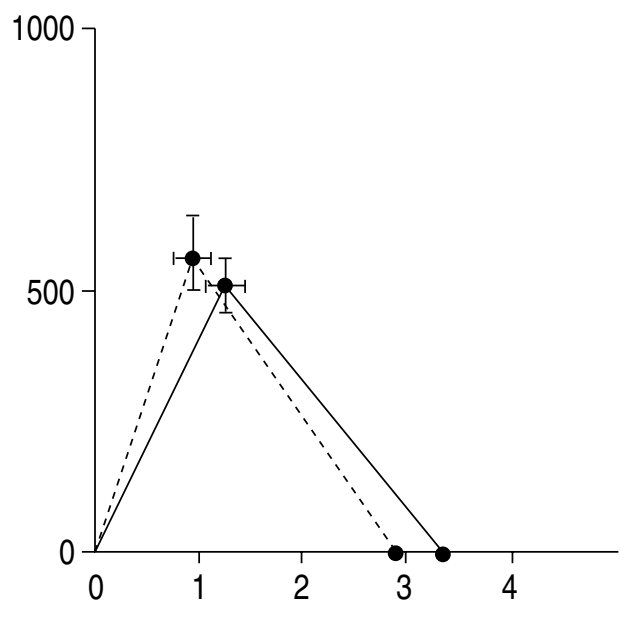

T s

Fig. 6. - Mean respiratory cycle during loaded breathing before and after inspiratory muscle training (IMT): a) in Group 1; and b) in Group 2. Mean \pm 1 SEM is represented for VT and T. _ : basal; ___ : post-IMT. VT: tidal volume; Tr: inspiratory time.
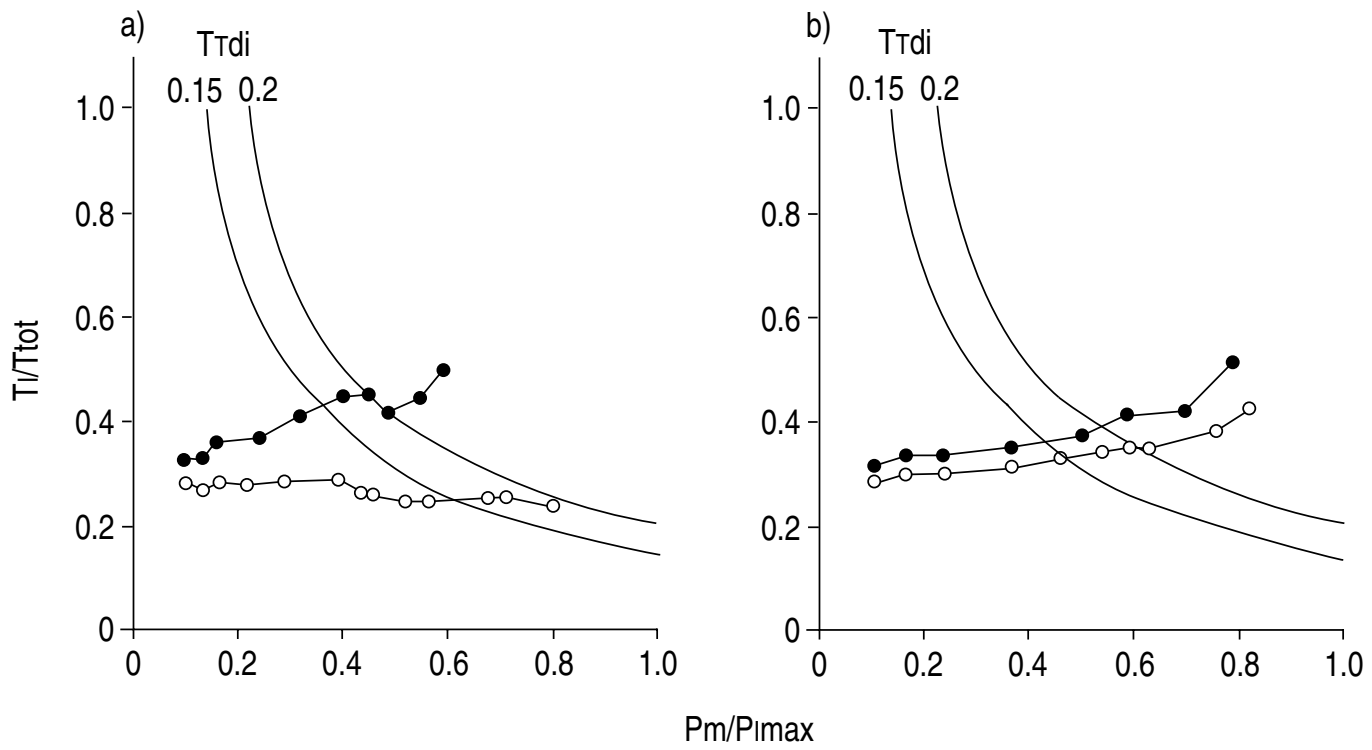

Fig. 7. - Pressure time index (PTX) during breathing with external loads before and after inspiratory muscle training (IMT): a) in Group 1; and b) in Group 2. Each dot corresponds to the mean value for each of the applied loads. Curved lines enclose the area of critical tension time beyond which diaphragmatic fatigue develops, according to Bellemare and Grassino [18]. ——— : basal; ——— : post-IMT: Pm: mouth pressure; PImax: maximum inspiratory mouth pressure; TI/Ttot: duty cycle (fraction of inspiration to total duration of breathing cycle); TTdi: tension time isopleths of the diaphragm.

before training fell on the fatigue area when Pm was $40 \%$ Pimax. After training, this critical area is reached in Group 1 only when a Pm of approximately 65\% Pimax was used, because their TI/Ttot for each load diminished with training. In Group 2, although $\mathrm{TI} /$ Ttot was slightly reduced, the PTX indices were practically unchanged. This is true even if we use a PTX of 0.24 as a fatigue threshold, with which $60 \%$ PImax could be indefinitely sustained $[17,21]$.

\section{Spirometry}

No significant changes in $\mathrm{VC}$ or $\mathrm{FEV}_{1}$ were observed after training within or between groups.

\section{Discussion}

In agreement with previous reports [9-14], our study confirms that the magnitude of the load used for inspiratory muscle training is a critical determinant of the results in patients with CAL; with an adequate load, IMT has a favourable effect on inspiratory muscle function, dyspnoea and physical capacity. Our study also shows that maximal inspiratory muscle power output is useful for evaluating the effects of training, and that patients can develop a strategy to cope with respiratory loads without reaching the critical area of inspiratory muscle fatigue [18].

In the present study, we used $30 \%$ Pimax as a target load, based on the report of LARSON et al. [9], who 
employed the same training device. With this load, all our patients were able to breathe for $15 \mathrm{~min}$ without discomfort. When using the patients as their own controls, IMT with $30 \%$ of Pimax produced significant increment in all of the parameters measured. However, when the two groups were compared after training, we did not observe significant differences in endurance, pattern of breathing and 6MWD, probably due to the fact that for some patients, even the minimal load $\left(7 \mathrm{cmH}_{2} \mathrm{O}\right)$ might have been high enough for endurance training. Furthermore, breathing repetitively against a low load may have increased inspiratory muscle endurance.

We believe that the changes observed in Group 1 are attributable to IMT and not to other factors, such as changes in treatment, learning effect of repeated measurements, or spontaneous variations of the disease. During the run-in period, medication was optimized in both groups and all measurements were performed $10 \mathrm{~min}$ after three puffs of $100 \mu \mathrm{g}$ salbutamol, so that the possibility of spontaneous variations of bronchomotor tone was reduced. No substantial changes in medication or other medical interventions occurred in either of the two groups during the study. Placebo effect from frequent contacts with the physician and/or nurse, and of repeated measurements can be excluded, since the same protocol was used for both groups.

Baseline inspiratory muscle function indices, although slightly lower in Group 2, were not significantly different between the two groups, so it is unlikely that the basal conditions may account for the lack of effect of the low load observed in Group 2. In addition, after completing the study period, the patients in Group 2 were submitted to further training with the $30 \%$ load for their own benefit and only some of the parameters were evaluated. An increment of $30 \pm 8 \%$ in Pimax, $89 \pm 28 \%$ in IMPO, and $29 \pm 14 \%$ in SIP were observed. The 6MWD increased $56 \pm 20 \mathrm{~m}$ and the dyspnoea transition index reached $4.2 \pm 0.8$ points. These results were comparable to those observed after training in Group 1 and confirm that the magnitude of the load used for training is critical.

It was not possible to blind the operators performing the control measurements, because they had to adjust the valve according to the measured Pimax, but a conscious effort was made to standardize coaching emphasis. Limitations for double-blind IMT studies have been pointed out by DeKHUIJZEN et al. [22] who questioned the certainty of the blinding used by GuYATT et al. [23] in a recent study.

The most likely explanation for our favourable results is that we used a device that assures a constant and sufficient target load (30\% of the patient's Pimax) independent of the breathing pattern. Other resistive training valves require a complicated control system to assure that the target pressure is reached and that the patient's breathing pattern is maintained $[10,11,14]$. Since the threshold valve does not require close supervision, it is adequate for home training. The good results of WEINER et al. [24], who trained asthmatic patients with the same device, are consistent with our observations.

Regarding the effect of training on inspiratory muscle strength, our results are similar to those reported by other studies using a sufficient target load [9-11, 13]. Results for endurance cannot be compared, since we used SIP, whilst most of the other studies have evaluated Tlim (endurance time).

In our study, we included measurements of maximal inspiratory flow and muscle power output, and both indices increased significantly with training, suggesting that IMT increases the velocity of contraction of the inspiratory muscles. The improvement in power output was considerably larger than that observed in the other indices, probably representing the added effect of IMT on strength and on velocity of contraction. In 6 of the 10 patients of Group 1, the improvement of IMPO was due to an increase in both flow and pressure; in 3, it was mainly due to an increase in flow; and, in the remaining 1 , to an increase in pressure. In Group 2 only 3 patients increased their IMPO and it was due to an increment in both factors. These results are in agreement with those reported by BELMAN and SHADMEHR [10], who also showed that IMT increases $\dot{\text { max. }}$

Our data suggest that the velocity of contraction of inspiratory muscles may be an important factor in the performance of these muscles in CAL patients, in whom power output is severely reduced. The improvement of $\dot{V}$ max and IMPO with training may be attributed to changes in the intrinsic contractile properties of the muscle fibres or, more probably, to a different recruitment of muscle fibres.

During the measurement of inspiratory muscle power, we also recorded the breathing pattern, so that it was possible to evaluate how the patients breathed when submitted to external loads. After training with 30\% PImax, the pattern of breathing was characterized by an increment of $\mathrm{V}_{\mathrm{T}}$, whilst $\mathrm{T}_{\mathrm{I}}$ was reduced, indicating an increase in mean inspiratory flow and, therefore, in the velocity of contraction of the inspiratory muscles. In addition, as Ttot did not change, the expiratory time was consequently prolonged. This probably means that patients were able to reduce their lung volume during expiration and, thus, improve the mechanical position of the diaphragm before the next inspiration. This pattern of breathing, in conjunction with greater respiratory muscle strength and endurance, may place these patients in an advantageous situation for coping with increased loads. In addition, the PTX values observed after training in Group 1 demonstrated that their inspiratory muscles were able to overcome greater loads and to develop greater force without falling into the fatigue area described by BELlemare and GRASSINO [18] for the diaphragm.

In the group trained with a low load, $\mathrm{V}_{\mathrm{T}}$ and $\mathrm{VT}_{\mathrm{T}} \mathrm{TI}$ also increased moderately, and TI was mildly reduced but, as the frequency of breathing increased, Te decreased.

Few studies have evaluated the effect of training on the pattern of breathing during loaded breathing [9, 25]. LARSON et al. [9] found no significant changes in TI/Ttot, after 1 and 2 months of training, but their data show a tendency to a shorter TI/Ttot. FLynN et al. [25], on the other hand, observed a reduction in $\mathrm{T}_{\mathrm{I}} / \mathrm{Ttot}$ and an increase in $\mathrm{V}_{\mathrm{T}} / \mathrm{TI}_{\mathrm{I}}$, consistent with our results.

Although the final aim of IMT is to improve the patient's quality of life, we found very few studies that have 
evaluated changes in dyspnoea with training [11, 13]. The improvement that we observed is of the same magnitude as that reported by HARVER et al. [11], who also used Mahler's transitional dyspnoea index. In our study, 9 of the 10 patients trained with a high load showed a reduction of dyspnoea. These changes did not correlate significantly with any of the physiological measurements, but when both groups were analysed together, a significant correlation between the changes in PImax and the focal transitional index of dyspnoea was found. HARVER et al. [11] also showed a significant correlation between the improvement in dyspnoea and the changes in PImax measured at residual volume (RV), when they grouped their study and control subjects.

PAtTessio et al. [13] assessed breathlessness during loaded breathing, and demonstrated that, after training, Borg's scale score was significantly lower for each load applied. These authors also found a significant correlation between Pimax and Borg scale, before and after training. They concluded that training reduces the sensation of breathlessness by means of an increase in inspiratory muscle strength and endurance.

The lack of correlation between the improvement of dyspnoea and the increment of PImax observed in our patients after training with a high load, may be due to the small number of subjects, or, more probably, because dyspnoea is not completely dependent on inspiratory muscle strength.

In 3 of the Group 2 patients, who had a very low PImax, the lowest load of the threshold pressure device represented approximately $17 \%$ of their Pimax. In this subgroup of patients, inspiratory muscle strength, power output and endurance improved practically to the same degree as in the high load group.

The increments in the 6MWD, which we observed after training, were comparable to the values reported in the literature $[2,9,12,13]$. As shown in figure 4 , the improvement was more marked in those patients with the lowest basal values. We did not find a significant relationship between this improvement and any of the other measurements performed.

In a recently published meta-analysis, SMITH et al. [8] concluded that there is little evidence for a clinical benefit of IMT in patients with chronic airflow limitation. However, they pointed out that the studies that use a high load for training may warrant further investigation. Indeed, in the five studies in which the load used for training was controlled, a high enough load improved strength and/or endurance.

The improvement in inspiratory muscle function with training may represent an increase in inspiratory muscle reserve, which may avoid or delay fatigue development during acute increases of respiratory load, as suggested in figure 7 . In addition, the breathing strategy employed during loaded breathing, may also help during exacerbation of symptoms. This suggests that IMT in CAL patients may be a useful therapeutic resource, provided that the imposed load is high enough to obtain a training effect on these muscles. This can be achieved with the use of the threshold inspiratory trainer, which simplifies the procedure, since the load is practically independent of the breathing pattern and does not need constant supervision.

Acknowledgements: The authors thank L. Villarroel for his statistical advice and M.E. Mora for her secretarial assistance.

\section{References}

1. Andersen JB, Dragsted L, Kam T, Johansen JH, Nielsen $\mathrm{KB}$, Karbo E. Resistive breathing training in severe obstructive pulmonary disease. A pilot study. Scand $J$ Respir Dis 1977; 60: 151-155.

2. Pardy RL, Rivington RM, Despas PJ, Macklem PT. The effect of inspiratory muscle training on exercise performance in chronic airflow limitation. Am Rev Respir Dis 1981; 123: 426-433.

3. Sonne LJ, Davis JA. Increased exercise performance in patients with severe COPD following inspiratory resistive training. Chest 1982; 81: 436-439.

4. Moreno RH, Moreno R, Giugliano C, Lisboa C. Entrenamiento muscular inspiratorio en pacientes con limitación crónica del flujo aéreo. Rev Méd Chile 1983; 111: 647-653.

5. Jederlinic P, Muspratt JA, Miller MJ. Inspiratory muscle training in clinical practice. Physiologic conditioning or habituation to suffocation? Chest 1984; 86: 870-873.

6. Ambrosino N, Paggiaro PL, Contini RV. Failure of resistive breathing training to improve pulmonary function test in patients with chronic obstructive pulmonary disease. Respiration 1984; 45: 455-459.

7. Belman MJ, Thomas SG, Lewis MI. Resistive breathing training in patients with chronic obstructive pulmonary disease. Chest 1986; 90: 662-669.

8. Smith K, Cooh D, Guyatt GH, Madhavan J, Oxmen AD. Respiratory muscle training in chronic airflow limitation: a meta-analysis. Am Rev Respir Dis 1992; 145: 533-539.

9. Larson JL, Kim MJ, Sharp JT, Larson DA. Inspiratory muscle training with a pressure threshold breathing device in patients with chronic obstructive pulmonary disease. Am Rev Respir Dis 1988; 138: 689-696.

10. Belman MJ, Shadmehr R. Targeted resistive ventilatory muscle training in chronic obstructive pulmonary disease. J Appl Physiol 1988; 65: 2726-2735.

11. Harver A, Mahler DA, Daubenspeck JA. Targeted inspiratory muscle training improves respiratory muscle function and reduces dyspnea in patients with chronic obstructive pulmonary disease. Ann Intern Med 1989; 111: 117-124.

12. Goldstein R, Rosie JD, Long S, Dolmage T, Avendaño MA. Applicability of a threshold loading device for inspiratory muscle testing and training in patients with COPD. Chest 1989; 96: 564-571.

13. Patessio A, Rampulla C, Fracchia C, et al. Relationship between the perception of breathlessness and inspiratory resistive loading: report on a clinical trial. Eur Respir $J$ 1989; 2 (Suppl. 7): 587s-591s.

14. Dekhuijzen PNR, Folgening HTM, van Herwaarden CLA. Target-flow inspiratory muscle training during pulmonary rehabilitation in patients with COPD. Chest 1991; 99: 128-133.

15. Black LF, Hyatt RE. Maximal respiratory pressures normal values and relationship to age and sex. Am Rev Respir Dis 1969; 99: 696-702. 
16. Martyn JB, Moreno RH, Paré PD, Pardy RL. Measurement of inspiratory muscle performance with incremental threshold loading. Am Rev Respir Dis 1987; 135: 919-923.

17. Nickerson BG, Keens TG. Measuring ventilatory muscle endurance in humans as sustainable inspiratory pressure. J Appl Physiol: Respirat Environ Exercise Physiol 1982; 52: 768-772.

18. Bellemare F, Grassino A. Effect of pressure and timing of contraction on human diaphragm fatigue. $J$ Appl Physiol: Respirat Environ Exercise Physiol 1982; 53: 1190-1195.

19. Mahler DA, Weinberg DH, Wells CK, Feinstein AR. The measurement of dyspnea. Contents, interobserver agreement, and physiologic correlate of two new clinical indexes. Chest 1984; 85: 751-758.

20. Mungall IPF, Hainsworth R. Assessment of respiratory function in patients with chronic obstructive airways disease. Thorax 1979; 34: 254-258.
21. Roussos CS, Fixley M, Gross D, Macklem PT. Fatigue of inspiratory muscles and their synergic behaviour. $J$ Appl Physiol: Respirat Environ Exercise Physiol 1979; 46: 897-904.

22. Dekhuijzen PNR, van Herwaarden CLD, Folgering HTM. Controlled trial of respiratory muscle training in chronic airflow limitation. (Letter to editor). Thorax 1993; 48: 96.

23. Guyatt G, Keller J, Singer J, Halcrow S, Newhouse M. Controlled trial of respiratory muscle training in chronic airflow limitation. Thorax 1992; 47: 598602.

24. Weiner P, Azgad Y, Ganam R, Weiner M. Inspiratory muscle training in patients with bronchial asthma. Chest 1992; 102: 1357-1361.

25. Flynn M, Barter C, Nosworthy JC, Pretto J, Rochford P, Pierce R. Threshold pressure training, breathing pattern, and exercise performance in chronic airflow obstruction. Chest 1989; 95: 535-543. 